\title{
Effects of Allicin on Hypertension and Cardiac Function in Chronic Kidney Disease
}

\author{
Ehécatl M. A. García-Trejo, ${ }^{1,2}$ Abraham S. Arellano-Buendía, ${ }^{1}$ \\ Raúl Argüello-García, ${ }^{3}$ María L. Loredo-Mendoza, ${ }^{4}$ Fernando E. García-Arroyo, ${ }^{1}$ \\ Mónica G. Arellano-Mendoza, ${ }^{2}$ María C. Castillo-Hernández, ${ }^{5}$ Gustavo Guevara-Balcázar, ${ }^{5}$ \\ Edilia Tapia, ${ }^{1}$ Laura G. Sánchez-Lozada, ${ }^{1}$ and Horacio Osorio-Alonso ${ }^{1}$ \\ ${ }^{1}$ Renal Physiopathology Laboratory, Department of Nephrology, Instituto Nacional de Cardiología "Ignacio Chávez", \\ 14080 Mexico City, Mexico \\ ${ }^{2}$ Chronic Degenerative Diseases Laboratory, Escuela Superior de Medicina, Instituto Politécnico Nacional, 11340 Mexico City, Mexico \\ ${ }^{3}$ Departamento de Genética y Biología Molecular, Centro de Investigación y de Estudios Avanzados, Instituto Politécnico Nacional, \\ 07360 Mexico City, Mexico \\ ${ }^{4}$ Histopathology Laboratory, Research Subdivision, School of Medicine, Universidad Panamericana, Donatello 43, \\ 03910 Mexico City, Mexico \\ ${ }^{5}$ Multidisciplinary Laboratory, Escuela Superior de Medicina, Instituto Politécnico Nacional, 11340 Mexico City, Mexico
}

Correspondence should be addressed to Horacio Osorio-Alonso; horace_33@yahoo.com.mx

Received 6 July 2016; Revised 21 September 2016; Accepted 27 September 2016

Academic Editor: Giuseppe Filomeni

Copyright ( 2016 Ehécatl M. A. García-Trejo et al. This is an open access article distributed under the Creative Commons Attribution License, which permits unrestricted use, distribution, and reproduction in any medium, provided the original work is properly cited.

\begin{abstract}
This work was performed to study the effect of allicin on hypertension and cardiac function in a rat model of CKD. The groups were control, CKD (5/6 nephrectomy), and CKD-allicin treated (CKDA) (40 mg/kg day/p.o.). Blood pressure was monitored (weekly/6 weeks). The cardiac function, vascular response to angiotensin II, oxidative stress, and heart morphometric parameters were determined. The CKD group showed hypertension and proteinuria. The coronary perfusion and left ventricular pressures were decreased in CKD group. In contrast, the vascular response to angiotensin II and expression of angiotensin II type 1 receptor (AT1R) were increased. These data were associated with the increment in morphometric parameters (weight of heart and left ventricle, heart/BW and left ventricular mass index, and wall thickness). Concurrently, the oxidative stress was increased and correlated inversely with the expression of Nrf2, Keap1, and antioxidant enzymes Nrf2-regulated. Allicin treatment attenuated hypertension and improved the renal and the cardiac dysfunctions; furthermore, it decreased the vascular reactivity to angiotensin II, AT1R overexpression, and preserved morphometric parameters. Allicin also downregulated Keap1 and increased Nrf2 expression, upregulated the antioxidant enzymes, and reduced oxidative stress. In conclusion, allicin showed an antihypertensive, nephroprotective, cardioprotective, and antioxidant effects, likely through downregulation of AT1R and Keap1 expression.
\end{abstract}

\section{Introduction}

Chronic kidney disease $(\mathrm{CKD})$ is considered as one of the most important diseases with a great burden on health care systems. As CKD progresses, it often leads to serious cardiovascular (CV) events. The patients with CKD are more likely to die of CV disease (CVD) than to progress to kidney failure $[1,2]$. In fact, the risk of CV mortality is 10 -fold to
20 -fold higher in these patients than in age- and gendermatched control subjects without CKD $[3,4]$. There is a strong relationship between CKD and CVD which could be explained by a typical clustering of several risk factors in CKD, such as hypertension, oxidative stress, proteinuria, volume overload, activation of the renin-angiotensin system, and other autocrine and paracrine mechanisms [5]. These factors might be activated independently of hemodynamic 
overload. With time, abnormalities in both structure and function are observed and occur even at the earliest stages of CKD without a manifest CVD [6]. A fundamental response of cardiomyocyte and left ventricular wall to intrinsic and biochemical stress in CKD is hypertrophy, which at first stages may be successfully compensatory but inevitably will progress to dilation and heart failure.

Despite the variety of drugs for the management of CKD, the cardiovascular complications continue as the leading cause of death in CKD patients. Many studies have documented the beneficial effect of functional foods and nutrients on cardiovascular diseases [7].

Although several reports have suggested that fresh garlic extract has protective actions against cardiovascular disorders, including stroke, coronary artery disease, and hypertension, the precise mechanism responsible for the effects remain to be defined [8-11]. Blood pressure lowering properties of garlic appear to come from the bulb portion of the plant and have been attributed to sulphur-containing compounds. Among these, allicin (allyl 2-propenethiosulfinate or diallyl thiosulfinate) is thought to be one of the main bioactive, organosulfur compounds synthesized in garlic. Allicin is naturally produced from the stable precursor S-allyl cysteineS-oxide (alliin) by the action of the enzyme alliinase when garlic cloves are crushed or macerated [12].

Recent studies have shown that allicin treatment reduces systemic blood pressure in spontaneously hypertensive rats and protects against coronary endothelial dysfunction and right heart hypertrophy in hypertensive rats $[12,13]$. Despite the studies supporting the vasoprotective effects of garlic, the role of allicin on cardiac function in CKD still remains unknown. Therefore, the present study was aimed at investigating the effects of allicin on hypertension and cardiac function in an experimental model of CKD.

\section{Material and Methods}

2.1. Reagents. Angiotensin II (Ang II), dichloromethane, diallyl disulphide, hydrogen peroxide, 4-nitrophenol, tetramethoxypropane, dinitrophenylhydrazine, methanesulfonic acid, and 1-methyl-2-phenylindole were purchased from Sigma-Aldrich (St. Louis, MO, USA). All other chemicals used were of the highest purity available.

2.2. Experimental Design. Male Wistar rats weighing 280$300 \mathrm{~g}$ of body weight were used. The rats were randomly distributed into three groups: control or sham (C), chronic kidney disease (CKD) [induced by subtotal renal ablation $(5 / 6 \mathrm{Nx})]$, and chronic kidney disease allicin-treated (CKDA) $(40 \mathrm{mg} / \mathrm{kg} /$ day, p.o.). All experimental groups were maintained under laboratory diet, water ad libitum, 12hour light/dark cycles, and temperature at $21^{\circ} \mathrm{C}$ and relative humidity at $70 \%$ for six weeks.

2.3. Ethics Statement. This study was performed in accordance with the Guide for the Care and Use of Laboratory Animals, published by the US National Institutes of Health, and approved by the Research Committee of the National Institute of Cardiology I. Ch. and by the Mexican Federal
Regulation for animal experimentation and care (NOM-062ZOO-2001) and for the disposal of biological residues (NOM087-ECOL-1995).

2.4. Allicin. Allicin was produced by oxidation of diallyl disulphide as previously reported [14]. In brief, $1 \mathrm{~g}$ diallyl disulphide was dissolved in $5 \mathrm{~mL}$ acetic acid under stirring in an ice bath. Hydrogen peroxide $(1.5 \mathrm{~mL}, 30 \% \mathrm{v} / \mathrm{v})$ was added stepwise and the reaction was allowed to proceed for $30 \mathrm{~min}$. Afterwards, the reaction was kept at $13^{\circ} \mathrm{C}$ for $20 \mathrm{~min}$; then, it was put again in ice bath for $5 \mathrm{~h}$, stopped with $15 \mathrm{~mL}$ distilled water at $\mathrm{pH} 6.5$, and extracted with $30 \mathrm{~mL}$ dichloromethane. After 5 extractions with $5 \%(\mathrm{w} / \mathrm{v}) \mathrm{Na}_{2} \mathrm{CO}_{3}(20 \mathrm{~mL}$ each) and 3 extractions with distilled water $(20 \mathrm{~mL}$ each), the solvent was left to evaporate until yellowish oil (allicin) remained. For stabilization and storage, allicin was resuspended in water at $2.5 \%(\mathrm{w} / \mathrm{v})$ and kept at $-70^{\circ} \mathrm{C}$ until used.

\subsection{Induction of Experimental Model of Chronic Kidney} Disease. Under anesthesia with isofluorane, subtotal renal ablation was performed by removal of the right kidney and selective infarction of approximately two-thirds of the left kidney by ligation of two or three branches of the renal artery $(5 / 6 \mathrm{Nx})$. Sham operation consisted of ventral laparotomy and manipulation of the kidneys and renal pedicle without destruction of renal tissue. The muscle and skin incisions were sutured with polypropylene suture. The animals were returned to the animal facility for surgery recovery [15].

2.6. Systolic Blood Pressure Record (SBP). After $5 / 6 \mathrm{Nx}$, the systolic blood pressure (SBP) was monitored weekly during six weeks by a validated tail-cuff plethysmography method using conscious rats (XBP-1000 Kent Scientific, CT, USA).

2.7. Renal Function. At six weeks of follow-up, rats were placed in metabolic cages (Nalgene, Rochester, NY, USA) to collect $24 \mathrm{~h}$ urine. Urine samples were centrifuged at $5000 \times \mathrm{g}$ for 15 minutes to remove debris, and the supernatant was analyzed. The urinary variables measured were diuresis, creatinine, urea (IL 300 plus, Clinical Chemistry Analyzer, Instrumentation Laboratory, Bedford, MA, USA), and proteinuria.

2.8. Assessment of Cardiac Function. The rats were anesthetized intraperitoneally with sodium pentobarbital $(60 \mathrm{mg} / \mathrm{kg})$ and the complete lack of pain response was assessed by determining pedal withdrawal reflex. Then, sodium heparin was injected $(1000 \mathrm{U} / \mathrm{kg})$ and 5 min later a midsternal thoracotomy was performed. The chest was opened, and a loose ligature was passed through the ascending aorta. The heart was trimmed of noncardiac tissue and perfused in a retrograde fashion via a nonrecirculating perfusion system at constant flow. Coronary flow was adjusted with a variablespeed peristaltic pump (Harvard Apparatus, model 1215 Holliston, MA, USA). An initial perfusion rate of $15 \mathrm{~mL} / \mathrm{min}$ for $5 \mathrm{~min}$ was followed by a $25 \mathrm{~min}$ equilibration period at a perfusion rate of $8 \mathrm{~mL} / \mathrm{min}$. The perfusion medium was Krebs-Henseleit solution with the following composition (mM): $\mathrm{NaCl}$ 117.8; $\mathrm{KCl} 6 ; \mathrm{CaCl}_{2}$ 1.75; $\mathrm{MgSO}_{4}$ 1.2; $\mathrm{NaH}_{2} \mathrm{PO}_{4}$ 
1.2; $\mathrm{NaHCO}_{3}$ 24.2; glucose 5; and sodium pyruvate 5. The solution was equilibrated with $95 \% \mathrm{O}_{2}-5 \% \mathrm{CO}_{2}, \mathrm{pH} 7.4$, and kept at $37.5^{\circ} \mathrm{C}$. A pair of stimulating electrodes, made of small stainless steel wire (vascular clamps/Fine Surgical Instruments, CA, USA), were placed $2 \mathrm{~mm}$ apart in the right atrioventricular groove. Pacing was achieved by applying electrical square pulses of $2 \mathrm{~ms}$ and at twice the electrical threshold at a rate of $4.5 \pm 0.3 \mathrm{~Hz}$.

After equilibration period, to determine the variations in coronary perfusion and systolic pressure, increments in coronary flow were performed $(6-14 \mathrm{~mL} / \mathrm{min})$.

To measure left intraventricular pressure, a latex fluid filled balloon ( $400 \mu \mathrm{L}$ Krebs solution) was placed in the ventricle and connected to a pressure transducer, adapted in turn, to a computerized data acquisition system (BIOPAC Systems, CA, USA). Measurements of LV function were obtained when the preparation achieved a steady state $(\approx 15 \mathrm{~min})$.

To assess coronary reactivity in heart, a dose-response assay was evaluated at increasing doses of Ang II $\left(10^{-9}, 10^{-8}\right.$, $10^{-7}$, and $10^{-6} \mathrm{M}$ ) for 10 minutes via a flow pump connected to the perfusion cannula.

2.9. Heart Morphology and Histology. At the end of the follow-up, six rats of each experimental group were anaesthetized with intraperitoneal injection of pentobarbital sodium $(40 \mathrm{mg} / \mathrm{kg})$. A polyethylene catheter filled with phosphate buffer $(0.2 \mathrm{M}, \mathrm{pH} 7.4)$ and heparin $(100 \mathrm{IU} / \mathrm{mL})$ was introduced into the ascending aorta. Then, the heart was arrested in diastole by injecting $1.0 \mathrm{~mL}$ of cadmium chloride $(100 \mathrm{mM})$ through the aortic catheter and was perfused retrogradely with phosphate buffer for $3 \mathrm{~min}$, followed by perfusion with $10 \%$ neutral buffered formalin solution for $15 \mathrm{~min}$. After perfusion-fixation, the heart was excised and atria and right ventricle were dissected from the LV and all pieces weights were recorded. The LV was cut into three transverse slices; the slice halfway between the base and the apex was embedded in paraffin, sectioned at $4 \mu \mathrm{m}$ intervals, and stained with HE [16].

Of each heart, four digital photomicrographs were obtained with the low power objective (5x) and, by an image analysis program (Axiovision Rel 4.8.2, Zeiss, Germany), the free wall thickness was calculated. The LVMI was defined as the value of the left ventricular weight (mg) divided by the total body weight $(\mathrm{g})$.

\subsection{Evaluation of Oxidative Stress in Heart}

Lipid Oxidation. 4-Hydroxynonenal (4-HNE) was measured using a standard curve of tetramethoxypropane. A solution of 1-methyl-2-phenylindole in acetonitrile : methanol $(3: 1)$ was added to heart homogenates and the reaction was started with $37 \% \mathrm{HCl}$ or methanesulfonic acid plus $\mathrm{FeCl}_{3}$, to measure 4HNE, respectively. Optical density was measured at $586 \mathrm{~nm}$ after $1 \mathrm{~h}$ of incubation at $45^{\circ} \mathrm{C}$. Data were expressed as nanomoles of 4-HNE per milligram of protein.

Oxidized Proteins. The determinations of carbonyl groups in the proteins were measured using the reaction with 2 , 4-dinitrophenylhydrazine (DNPH). Carbonyl groups were estimated by using the molar absorption coefficient of $22,000 \mathrm{M}^{-1} \cdot \mathrm{cm}^{-1}$ for DNPH derivatives, and its concentration was expressed as nmol carbonyl groups/mg protein.

2.11. Expression of Angiotensin II Type 1 Receptor (AT1R), Nuclear Factor (Erythroid-Derived 2) Like 2 (Nrf2), and Kelch-Like ECH-Associated Protein 1 (Keap1) in Heart. The frozen heart was ground to a powder and then mixed in ice-cold HEPES buffer (10 mM HEPES, $0.2 \%$ Triton X-100, $50 \mathrm{mM} \mathrm{NaCl}, 0.5 \mathrm{mM}$ sucrose, $0.1 \mathrm{mM}$ EDTA, protease, and phosphatase inhibitors) and homogenized with an ice-chilled Dounce homogenizer at $4^{\circ} \mathrm{C}$. An aliquot of the homogenate was stored and the rest was used to make cytosolic and nuclear extracts. This was spun at 10,000 rpm for $10 \mathrm{~min}$, and the supernatant was aliquoted and stored at $-70^{\circ} \mathrm{C}$ as the cytosolic extract. The pellet was suspended in ice-cold buffer (10 mM HEPES, $500 \mathrm{mM} \mathrm{NaCl}, 10 \%$ glycerol, $0.1 \mathrm{mM}$ EDTA, $0.1 \mathrm{mM}$ EGTA, 0.1\% IGEPAL, and protease and phosphatase inhibitors) and vortexed at $4^{\circ} \mathrm{C}$ for $15 \mathrm{~min}$ and centrifuged for $10 \mathrm{~min}$ at $14,000 \mathrm{rpm}$. The resulting supernatant was aliquoted and stored as the nuclear extract at $-70^{\circ} \mathrm{C}$. A small aliquot of heart homogenate, cytosolic, and nuclear extract was kept at $4^{\circ} \mathrm{C}$ for protein estimation by the Bradford method using bovine serum albumin as standard. Thirty $\mu \mathrm{g}$ of total protein was used to evaluate expression of AT1 receptor, Nrf2, and Keap1. Nuclear extracts were used for Nrf2 immunoblotting. Intensity values were normalized to a loading control (housekeeping) and expressed as arbitrary units of protein expression. Glyceraldehyde-3-phosphate dehydrogenase (GAPDH) and proliferating cell nuclear antigen (PCNA) were used as a loading control (housekeeping).

2.12. Immunofluorescence. Immunofluorescence analysis of Nrf2 was performed using $4 \mu \mathrm{m}$ sections from at least 2 animals per group, paraffin embedded renal tissue. After deparaffinization and rehydration, the samples were submitted to heat induced antigen retrieval in sodium citrate buffer (10 mM, pH 6.0) during 20 minutes. Next steps were as follows: incubation during 1 hour with a blocking solution (2\% bovine serum albumin, 5\% normal goat serum), 1 hour with the primary antibody (anti-Nrf2 rabbit polyclonal GeneTex GTX 103322) at a 1/50 dilution, and 1 hour with a secondary FITC-conjugated goat anti-rabbit antibody at a 1/100 dilution; all these reagents were diluted in TBS with $0.05 \%$ Tween ${ }^{\circledR} 20$. Then, the Tyramide Signal Amplification fluorescence kit from Perkin Elmer (NEL741E001KT) was used according to manufacturer instructions. Briefly, an antifluorescein HRP conjugated antibody was applied to the sections ( $30 \mathrm{~min}$ ), followed by incubation for 3 minutes with the amplification reagent. All the steps were performed at room temperature and the slides were washed with TBS with $0.05 \%$ Tween 20 after each step, except after the application of the blocking solution. For nuclear counterstaining, DAPI was used. The same microscope and software mentioned above for the histological assessment were utilized for the fluorescence labeled sections analysis. Microscopic images were obtained using a digital camera mounted on a light microscope (Axiophot 2, Zeiss, Germany). 
TABLE 1: Body weight and renal function parameters in the experimental groups studied.

\begin{tabular}{lccc}
\hline & Sham & CKD & CKDA \\
\hline Body weight $(\mathrm{g})$ & $386 \pm 4.59$ & $327.44 \pm 2.95^{*}$ & $360.33 \pm 1.85^{* \#}$ \\
Serum creatinine $(\mathrm{mg} / \mathrm{dL})$ & $0.41 \pm 0.01$ & $1.42 \pm 0.10^{*}$ & $1.08 \pm 0.04^{* \#}$ \\
Blood urea nitrogen $(\mathrm{mg} / \mathrm{dL})$ & $3.8 \pm 0.30$ & $56.11 \pm 2.71^{*}$ & $43.9 \pm 2.43^{* \#}$ \\
Urinary volume $(\mathrm{mL} / 24 \mathrm{~h})$ & $19.92 \pm 1.1$ & $32.86 \pm 3.36^{*}$ & $45.58 \pm 4.35^{* \#}$ \\
Urinary creatinine $(\mathrm{mg} / \mathrm{dL})$ & $34.6 \pm 2.74$ & $42.92 \pm 3.56^{*}$ & $35.59 \pm 3.42^{\#}$ \\
Urinary urea $(\mathrm{mg} / \mathrm{dL})$ & $115 \pm 8.50$ & $177.6 \pm 8.80^{*}$ & $180.1 \pm 10.84^{*}$ \\
Proteinuria $(\mathrm{mg} / 24 \mathrm{~h})$ & $12.32 \pm 0.95$ & $232.15 \pm 23.19^{*}$ & $125.29 \pm 13.1^{* \#}$ \\
\hline
\end{tabular}

CKD: chronic kidney disease; CKDA: chronic kidney disease treated with allicin. Data are expressed as mean \pm SEM of at least 6 animals from each experimental group. ${ }^{*} p<0.001$ versus control and ${ }^{\#} p<0.001$ versus CKD.

2.13. Statistical Analysis. All data are presented as means \pm SEM. Comparisons among group were made using oneway analysis of variance followed by Tukey's test by using GraphPad version 5.00 (GraphPad Software, La Jolla, CA, USA). Results were considered significant when $p<0.05$.

\section{Results}

At the beginning of the experiments, differences in the body weights among rats in all experimental groups were indistinguishable. However, at six weeks of follow-up, the body weight average was significantly lower in CKD group as compared with control group (Table 1). The allicin treatment favored weight gain when compared to the CKD untreated group

3.1. Renal Function. To validate the CKD model, renal function was evaluated through measurement of creatinine and blood urea nitrogen (BUN) in serum and urine, as well as diuresis and proteinuria. The CKD group showed statistically significant higher levels of creatinine and BUN in serum and urine and increased diuresis and proteinuria in comparison to those of the control group (Table 1).

Allicin treatment improved renal function evidenced by a significant reduction in creatinine and BUN levels in serum and urine as well as in proteinuria when compared with CKD group (Table 1).

3.2. Blood Pressure. Renal chronic disease is frequently associated with high blood pressure; therefore, we measured systolic blood pressure in the experimental groups by tailcuff method in conscious rats. At baseline, rats from all experimental groups had similar systolic blood pressure (Figure 1). However, at six week of follow-up, the group with CKD showed significantly higher systolic blood pressure as compared with control group. The systolic blood pressure was increased in a time-dependent fashion and at the end of the study reached $\approx 180 \mathrm{mmHg} \pm 6 \mathrm{mmHg}$. In contrast, control group remained with a blood pressure within normal range (Figure 1). Interestingly, allicin treatment partially but significantly prevented the increase in systolic blood pressure from the second week to the end of the study; thus rats in this group reached $140 \mathrm{mmHg}$ at week $6,40 \mathrm{mmHg}$ less compared to CDK group without treatment (Figure 1).

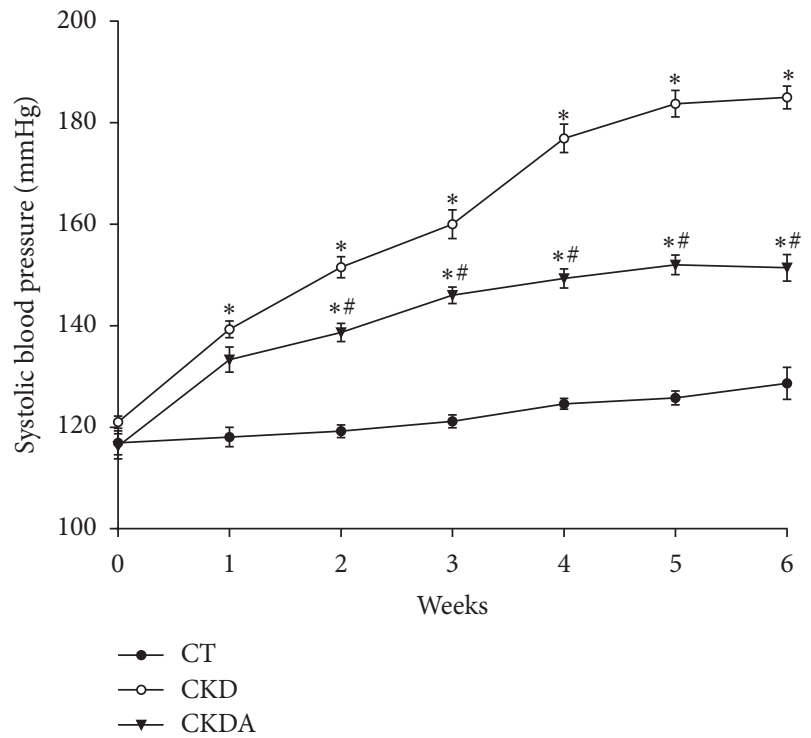

FIGURE 1: Systolic blood pressure in experimental groups by tail-cuff method. CT: control; CKD: chronic kidney disease; CKDA: chronic kidney disease treated with allicin. Values are expressed as mean \pm SD of at least 6 animals from each experimental group, ${ }^{*} p<0.05$ versus $C T$ and ${ }^{\#} p<0.05$ versus CKD.

3.3. Assessment of Cardiac Function In Vitro. To evaluate cardiac function in the various experimental groups, we determined the coronary perfusion pressure and left ventricular systolic pressure.

The coronary perfusion pressure flow relationship for heart is summarized in Figure 2(a). Control group depicted the normal heart response; thus increments in coronary flow rate from 6 to $10 \mathrm{~mL} / \mathrm{min}$ resulted in a proportional raise in coronary perfusion pressure; then an abrupt increment in perfusion pressure was obtained at flows of 12 and $14 \mathrm{~mL} / \mathrm{min}$ in this group. In contrast, CKD group showed a significantly blunted response, demonstrated by a flattened coronary perfusion pressure flow-dependent curve compared to control group (Figure 2(a)). Allicin treatment improved coronary perfusion pressure as compared to the CKD untreated group, although the effect was clearly appreciated from basal to hypervolemic coronary flow conditions (Figure 2(a)). 


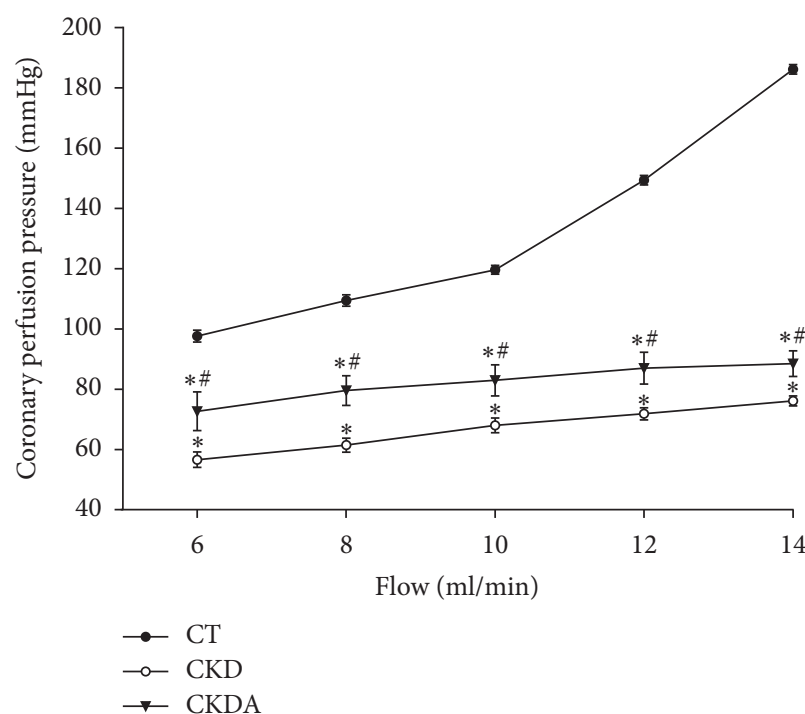

(a)

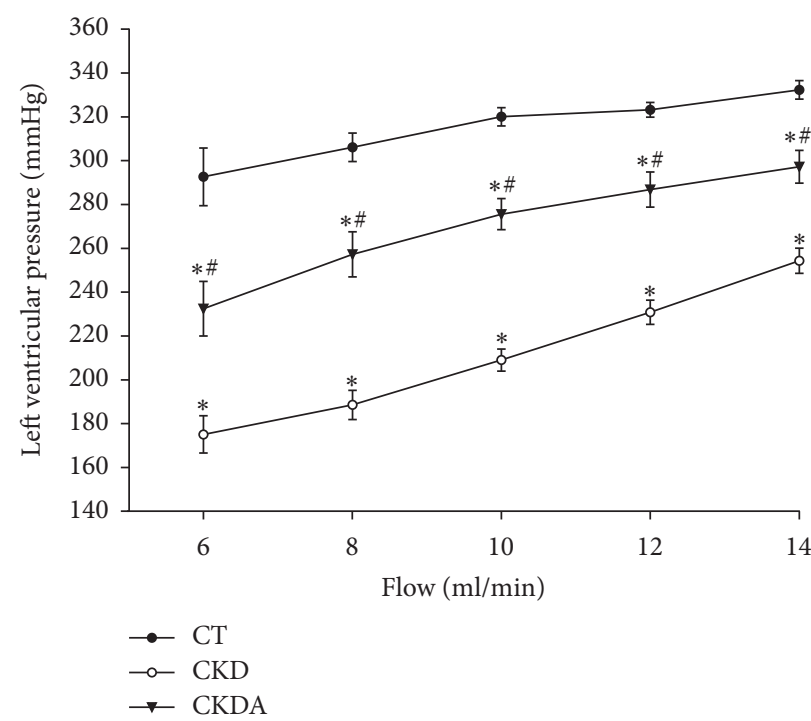

(b)

FIgURE 2: (a) Flow-dependent coronary perfusion pressure and (b) Flow-dependent left ventricular pressure. CT: control; CKD: chronic kidney disease; CKDA: chronic kidney disease treated with allicin. Values represent mean \pm SD of at least 6 animals from each experimental group. ${ }^{*} p<0.05$ versus $\mathrm{CT}$ and ${ }^{\#} p<0.05$ versus CKD.

The left ventricular pressure response to increase in coronary flow rate in the different groups is shown in Figure 2(b). The left ventricle pressure of CKD group increased in a flow-dependent manner. However, the left ventricular performance of these hearts was significantly lower than those of the control group (Figure 2(b)). Regarding the CKDallicin treated group, it showed an improvement in the left ventricular performance when compared with CKD group untreated, without reaching the normal values. However, the isolated heart from CKDA group showed a better response to variable coronary flow rate, from hypovolemic to hypervolemic conditions (Figure 2(b)).

3.4. Effect of Allicin on Vascular Reactivity to Angiotensin II and ATIR Expression. To assess vascular reactivity, perfused isolated hearts were stimulated with Ang II in a concentration-response curve. The Ang II infusion induced increases in coronary perfusion pressure in a concentrationdependent fashion in all experimental groups (Figure 3(a)). However, in the isolated heart from CKD group, the stimuli with Ang II increased coronary perfusion pressure significantly between each point $[\log M]$ compared with response observed in control group (Figure 3(a)), even at very low concentrations (from 0 to $-9[\log M]$ ). In the CKDA group, the Ang II concentration-response assay showed an increase in coronary perfusion pressure in a concentration-dependent way, but these increments were lower in CKDA than those observed in the CKD untreated group (Figure 3(a)). The effects induced by Ang II stimuli as well as the cardioprotective effect of allicin on the cardiac response to Ang II are clearly appreciated in Figure 3(b).

To better understand the mechanism involved in the improvement of the cardiovascular response to Ang II, we
TABLE 2: Gross cardiac measurements.

\begin{tabular}{lccc}
\hline & CT & CKD & CKDA \\
\hline Right atrium (mg) & $26.6 \pm 2.5$ & $31.67 \pm 2.2$ & $29.67 \pm 2.9$ \\
Left atrium (mg) & $24 \pm 4.5$ & $24.89 \pm 1.48$ & $23.33 \pm 2.01$ \\
Right ventricle (mg) & $263 \pm 20.9$ & $272 \pm 12.08$ & $239.7 \pm 25.94$ \\
Left ventricle (mg) & $726.8 \pm 21.27$ & $1025 \pm 41.04^{*}$ & $834 \pm 38.67^{* \#}$ \\
Heart (g) & $1.04 \pm 0.02$ & $1.35 \pm 0.04^{*}$ & $1.12 \pm 0.08^{* \#}$ \\
LVIM (mg/g) & $1.88 \pm 0.03$ & $3.12 \pm 0.1^{*}$ & $2.3 \pm 0.1^{\text {*\# }}$ \\
Heart/BW (g) & $2.69 \pm 0.04$ & $4.13 \pm 0.11^{*}$ & $3.12 \pm 0.17^{\text {*\# }}$ \\
\hline
\end{tabular}

CT: control; CKD: chronic kidney disease; CKDA: chronic kidney disease treated with allicin; LVMI: left ventricle mass index; BW: body weight. Data are expressed as mean \pm SEM of at least 6 animals from each experimental group. ${ }^{*} p<0.001$ versus control and ${ }^{\#} p<0.001$ versus CKD.

evaluated the protein level expression of Ang II type 1 receptor (AT1R) in heart. In the CKD group, the AT1R expression was increased compared with that of the control group. Allicin treatment partially decreased AT1R expression in comparison to that of the CKD untreated group (Figure 3(c)).

3.5. Measurement of Morphometric Variables. Upon gross observation, rats in the CKD group had visibly hypertrophic hearts compared with the control group. In this study, we did not observe differences in right atrium, left atrium, and right ventricle weights. However, a significant increase in heart and left ventricle weight, LVMI, and heart/BW index were observed in CKD group when compared with those of the control group (Table 2), suggesting the presence of left ventricular hypertrophy. Interestingly, the increase in left ventricle weight and LVMI in the CKD group was associated with global LV wall thickening (Figure 4), a sign of CVD [5]. The mean thickness LV free wall was significantly higher 

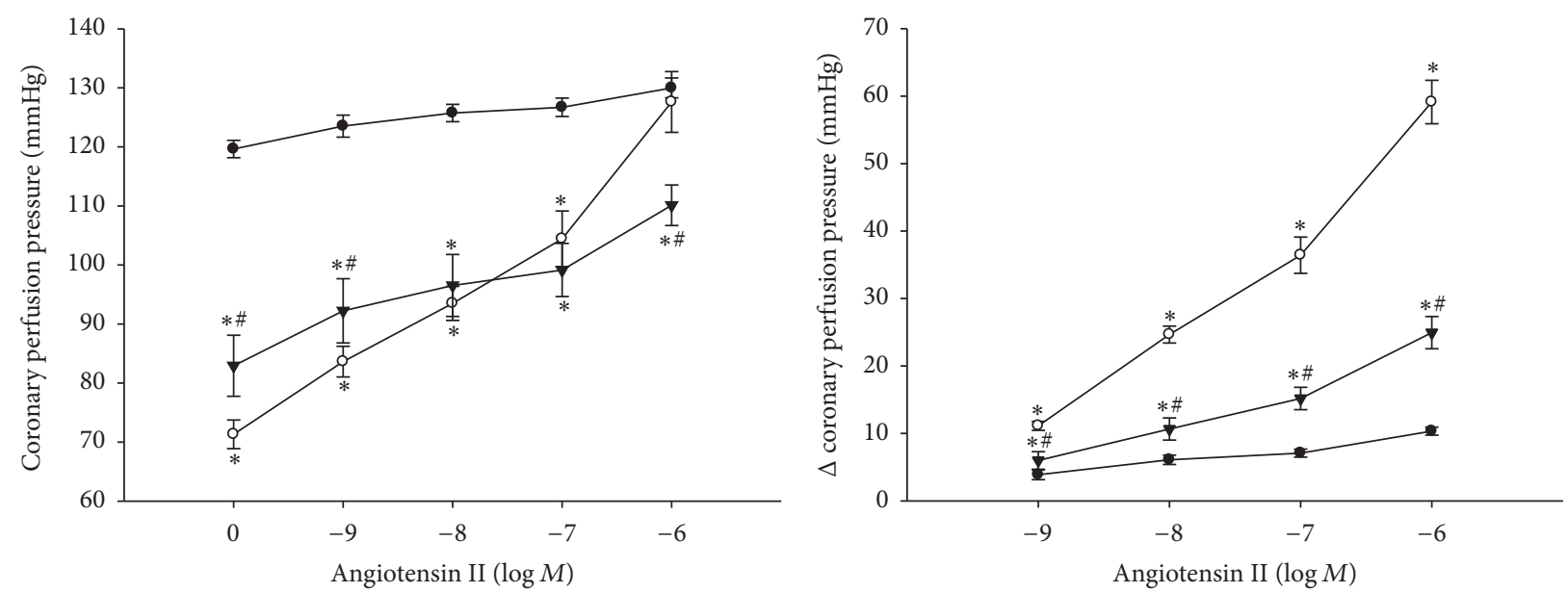

- $\mathrm{CT}$

- CKD

- $\mathrm{CT}$

- CKD

$\checkmark$ CKDA

(a)

(b)
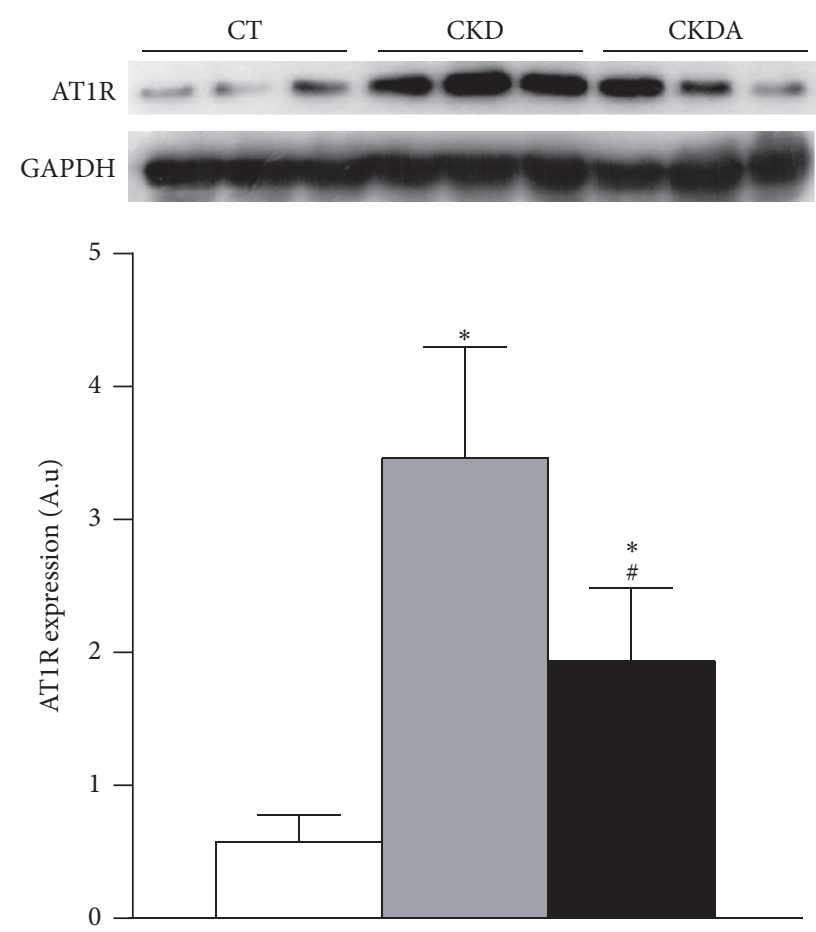

(c)

FIGURE 3: Effect of allicin treatment on (a) vascular reactivity to angiotensin II, (b) changes $(\Delta)$ of coronary perfusion pressure, and (c) angiotensin II type 1 receptor (AT1R) expression in heart. CT: control; CKD: chronic kidney disease; CKDA: chronic kidney disease treated with allicin. Values represent mean \pm SD of at least 6 animals from each experimental group. ${ }^{*} p<0.05$ versus $\mathrm{CT}$ and ${ }^{\#} p<0.05$ versus CKD.

in CKD group than that of the control group $(p<0.05)$. Importantly, allicin treatment prevented all morphologic alterations observed in heart samples from the CKD group such as the increment in LVMI, left ventricular weight, and wall thickness of heart (Table 2 and Figure 4).

3.6. Evaluation of Oxidative Stress in Heart. Oxidative stress is one of multiple molecular mechanisms involved in the etiology of hypertension, CVD, and CKD.
To assess oxidative stress in heart during CKD, lipid and protein oxidation were evaluated by measuring tissue content of 4-HNE and carbonylated proteins, respectively. In whole heart, lipid and protein oxidation were significantly increased in CKD group when compared to the control group (Figures 5(a) and 5(b)). This CKD-induced cardiac oxidative stress was decreased by allicin treatment (Figures 5(a) and 5(b)).

The expressions of Nrf2 and Keap1 were also assessed in total heart tissue, as this pathway is the master regulator of the 

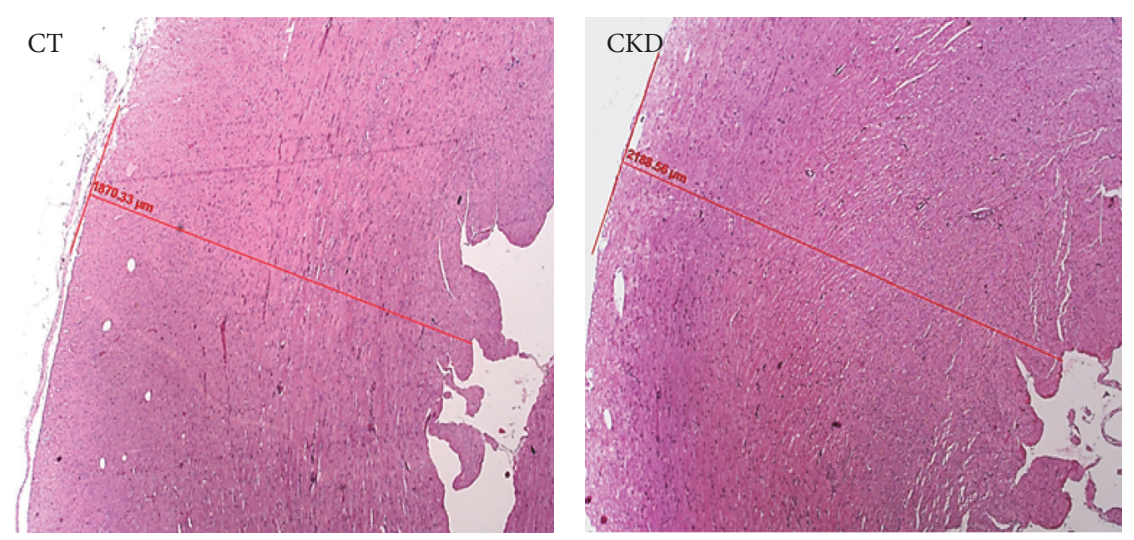

(a)

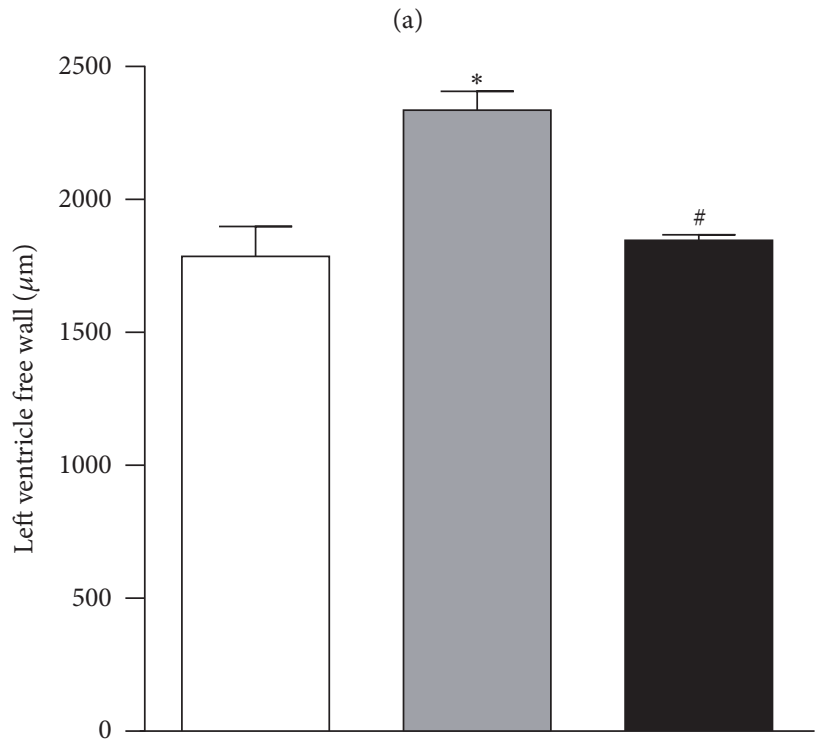

(b)

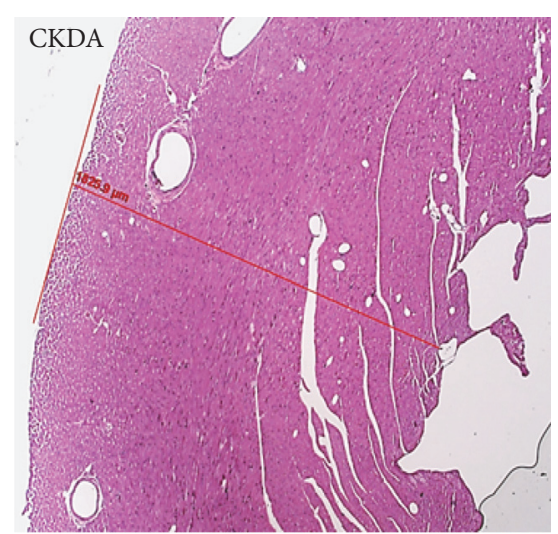

.

FIGURE 4: Left ventricle free wall portion photomicrograph (a) and quantitative analysis (b). CT: control; CKD: chronic kidney disease; CKDA: chronic kidney disease treated with allicin. Values represent mean \pm SD. ${ }^{*} p<0.05$ versus $\mathrm{CT}^{\text {and }}{ }^{*} p<0.05$ versus $\mathrm{CKD}$.

antioxidant cellular protection. After six weeks of follow-up, in heart from group with CKD, the Nrf2 and Keap1 protein expression was lower than that of the control group (Figures $5(\mathrm{c})$ and $5(\mathrm{~d})$ ). The allicin treatment restored the Nrf2 protein expression levels (Figure 5(c)). Additionally, allicin decreased the Keapl protein expression compared with group with CKD untreated and control group (Figure 5(d)).

After these observations, to determine if transcription mechanism was involved in the cardioprotective effect of allicin, we assessed the Nfr2 expression using a nucleienriched fraction. The expression of Nrf2 in the CKD group was lower compared to the control group. This effect CKDinduced was prevented by treatment with allicin (Figure 5(e)). These results were supported by microscopy analysis using immunofluorescence (Figure 6). The immunofluorescence labeling showed a control group depicting scarce positivity in nuclei. In the CKD group, we did not observe clear evidence of Nrf2 immunoreactivity compared with control group. In contrast, in the $\mathrm{CKD}$-allicin treated group was noticeable intense reactivity in nuclei compared with the CKD untreated (Figure 6).

Thus, we hypothesize that Nrf2 would stimulate the expression of its target genes. Therefore, we assessed the expression of endogenous antioxidant enzymes CAT, SOD, and GPx. The protein expression of CAT, SOD, and GPx was decreased in cardiac tissue from CKD group compared with control group. The allicin treatment restores this CKDinduced effect (Figure 7).

\section{Discussion}

In the present study, we evaluated the therapeutic effect of allicin on hypertension and cardiac function in a rat model of CKD. We provide evidence that allicin improved renal function, partially decreased systemic hypertension, improved the function of the heart, and prevented its remodeling, in addition to almost abolishing the oxidative stress. The protective effects of allicin were mediated by reducing the 


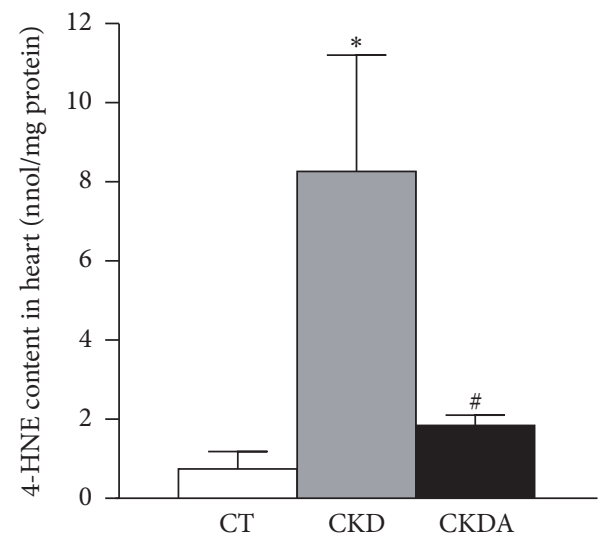

(a)
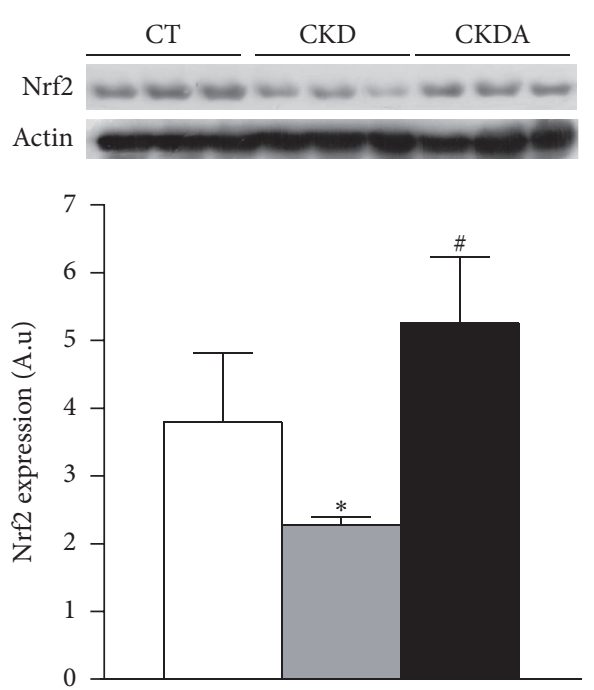

(c)

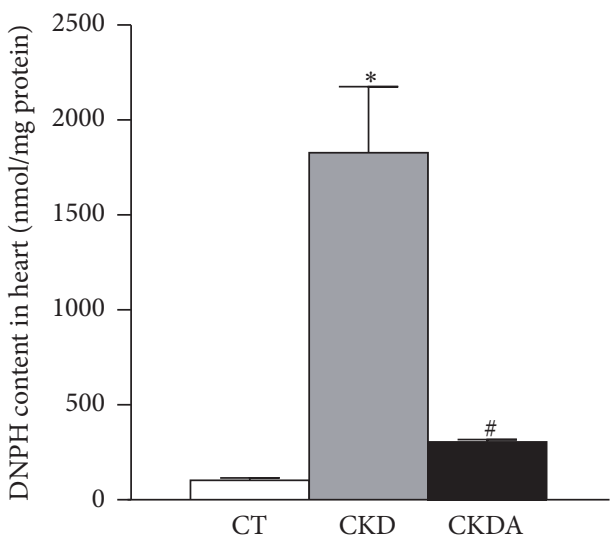

(b)
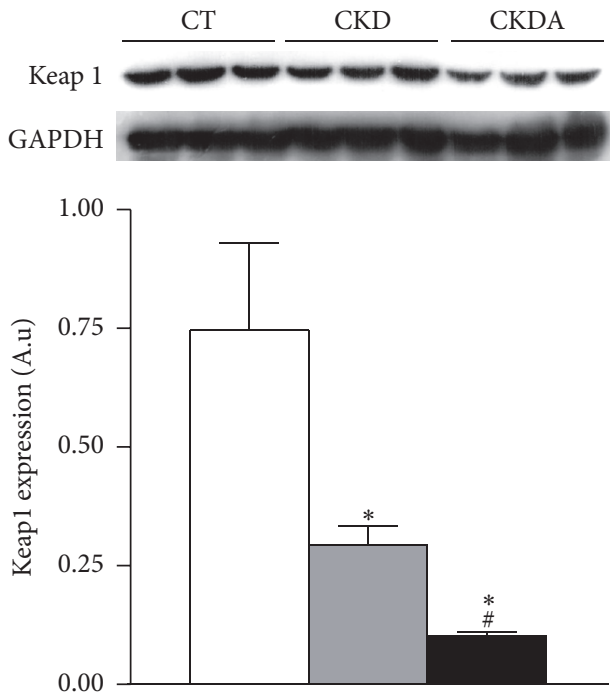

(d)
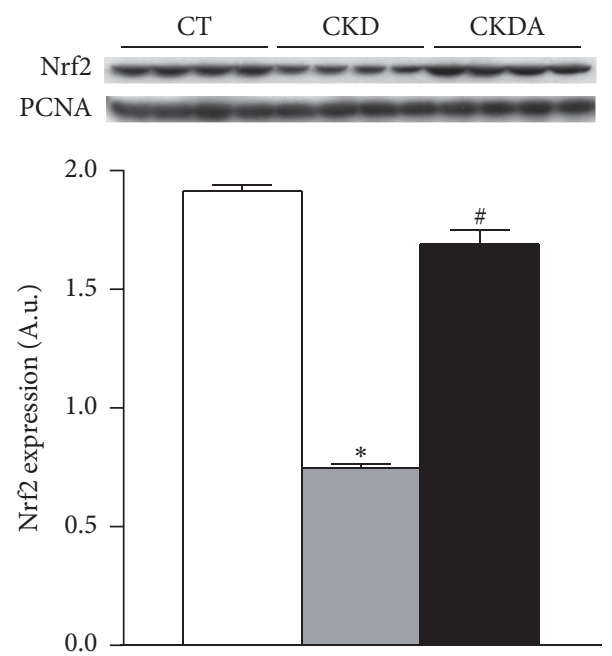

(e)

Figure 5: Evaluation of oxidative stress in heart. (a) Lipid oxidation, (b) protein oxidation, (c) Nrf2 expression, (d) Keap1 expression, and (e) nuclear expression of Nrf2. CT: control; CKD: chronic kidney disease; CKDA: chronic kidney disease treated with allicin. Values are resented as mean \pm SD of at least 6 animals from each experimental group. ${ }^{*} p<0.05$ versus CT and ${ }^{\#} p<0.05$ versus CKD. 

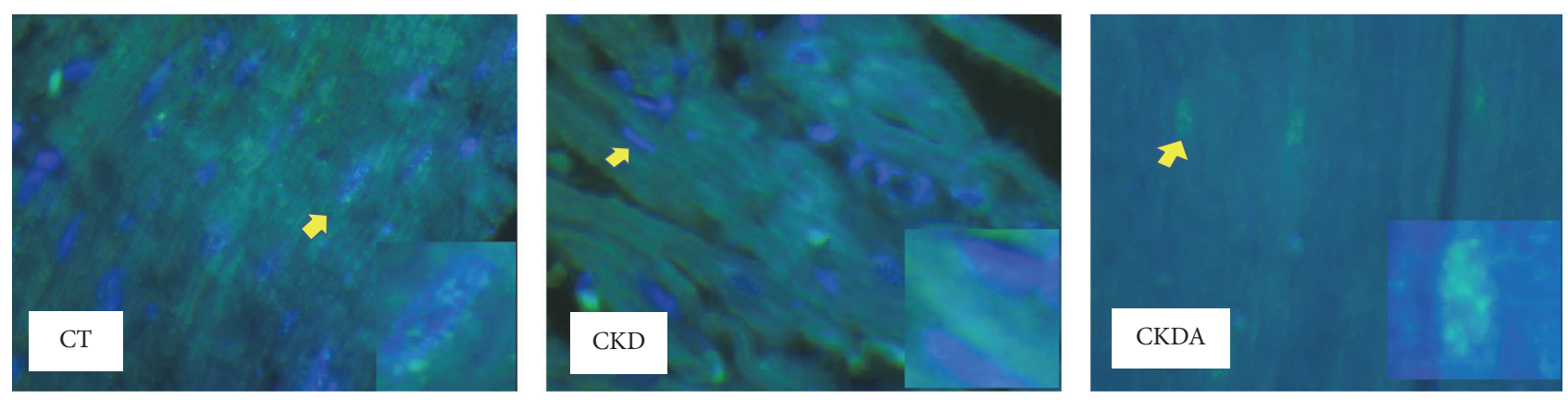

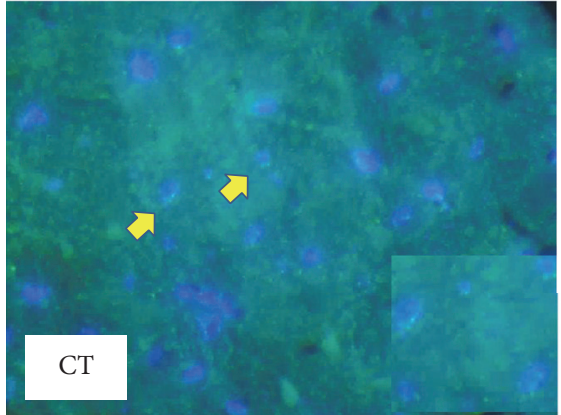

(a)

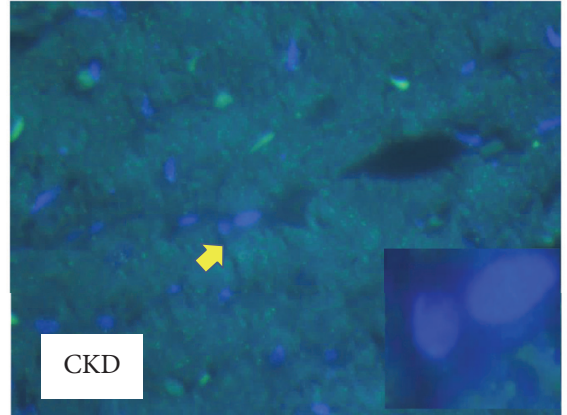

(b)

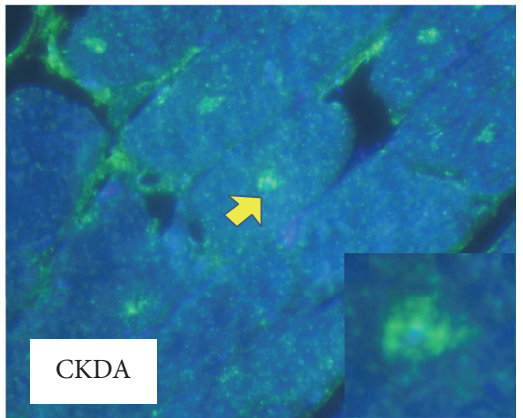

(c)

FIGURE 6: Localization and expression of Nrf2 in heart. (a) Control (CT), (b) chronic kidney disease (CKD), and (c) chronic kidney diseaseallicin (CKDA) treated. Representative heart sections micrographs showing immunoreactivity for Nrf2. Upper row longitudinal areas and lower row cross areas. Left column, control group depicting scarce positivity in nuclei; middle column, CKD group, with no evidence of reactivity; and right column, CKD-allicin treated group with intense reactivity in nuclei. Original magnification 100x.

AT1R and Keap1 expression. In contrast, allicin increased the Nrf2 expression and consequently their target genes (CAT, SOD, and GPx), which led to decrease in hypertension, oxidative stress, ultimately improving cardiac structure and performance.

The beneficial effects of garlic against cardiovascular disorders such as stroke, coronary artery disease and hypertension are well known [8-11]. It has been suggested that the active substance in garlic may be one of the sulphur compounds; among them, allicin is considered as one of the highest bioactive organosulphur compounds from garlic [12]. Despite the fact that the effect of whole garlic extract on hypertension is well known, the effects of allicin on blood pressure and renal and cardiac function specifically in CKD are scarce [17-19]. Thus, this study was designed to assay the usefulness of allicin in treatment of complications associated with CKD.

In our study, allicin improved the biochemical markers of renal dysfunction such as creatinine, blood urea nitrogen, diuresis, and proteinuria. To our knowledge, this is the first study showing the nephroprotective effects of allicin on an experimental model of CKD. In addition, treatment with allicin in a control group did not affected neither blood pressure nor renal function (data not shown). The CKD group showed a blood pressure progressive increment longitudinally in time, which allicin treatment reduced significantly from the early stages to the end of study. In agreement with our results, chronic oral administration of allicin reduced systolic blood pressure in different conditions such as spontaneously hypertensive rats, hypercholesterolemic rats, and fructose-induced hyperinsulinemic hyperlipidemic rats [12, 20, 21].

Our results on cardiac function showed a decrement in coronary perfusion pressure and left ventricular performance in CKD group. These results indicate a dysfunctional heart unable to adapt to pumping sufficient amounts of blood to meet acute metabolic demands of organs and tissues, for example, during physical exercise. This effect causes exercise intolerance, impairs quality of life, and has been associated with high morbidity and mortality. In contrast, the vascular response to Ang II was increased and this result was associated with the increased AT1 receptor expression in heart from CKD group. These data indicates hyperreactive cardiac endothelium, mainly to vasoconstrictors such as Ang II. In addition, our data from morphometric analysis suggest cardiac hypertrophy. It has been reported that the increased Ang II receptors contribute to the growth of the heart and hence to maintaining hypertrophy [22]. Abnormalities in both cardiovascular structure and function are observed early in the course of CKD [6], with the left ventricular hypertrophy as the most common abnormality in adult patients [5].

The alterations in cardiac function, vascular response to Ang II, AT1 receptor expression and morphometric analysis were attenuated by the allicin treatment. Previous studies demonstrated that garlic oil attenuates the impaired cardiac 

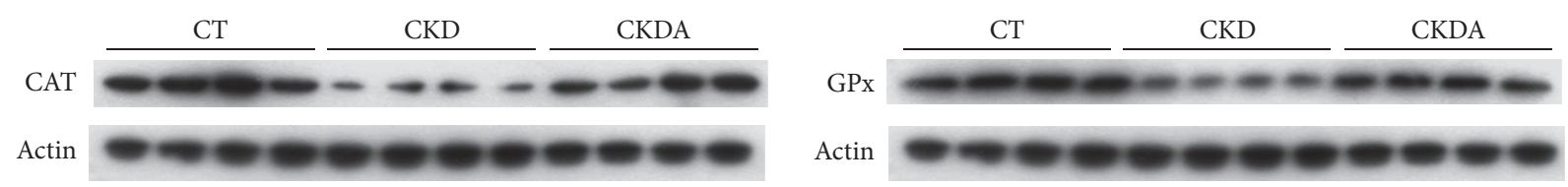

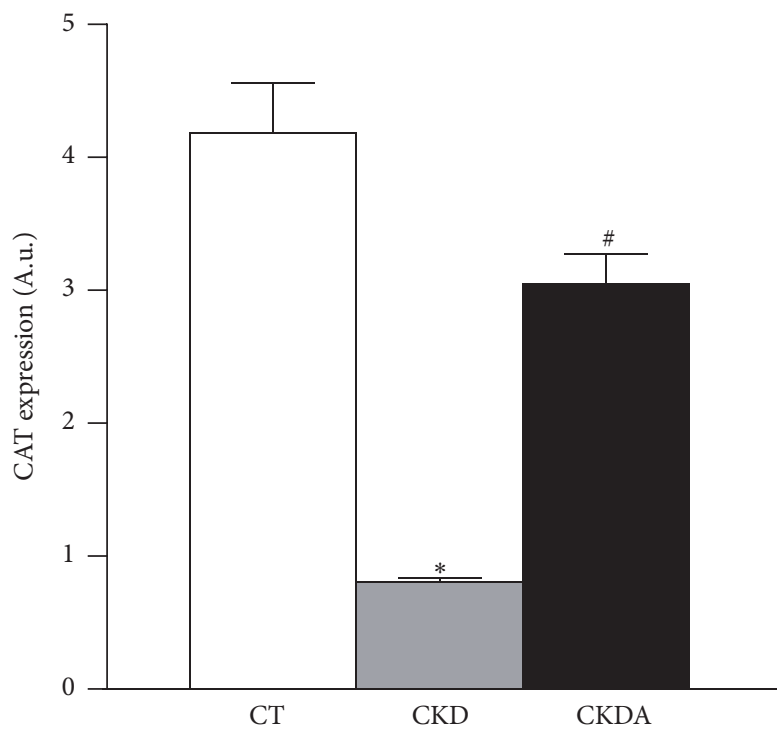

(a)

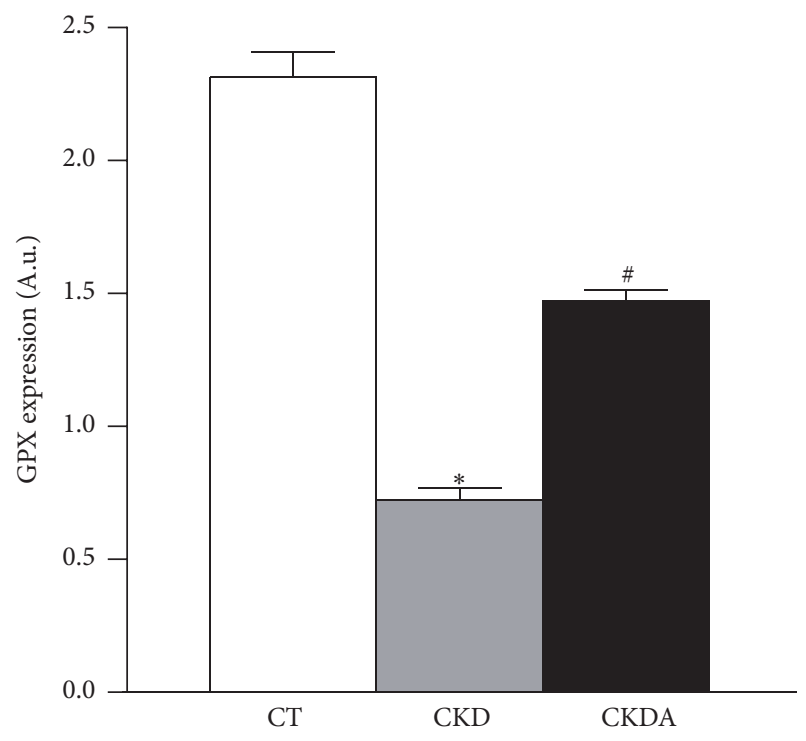

(b)
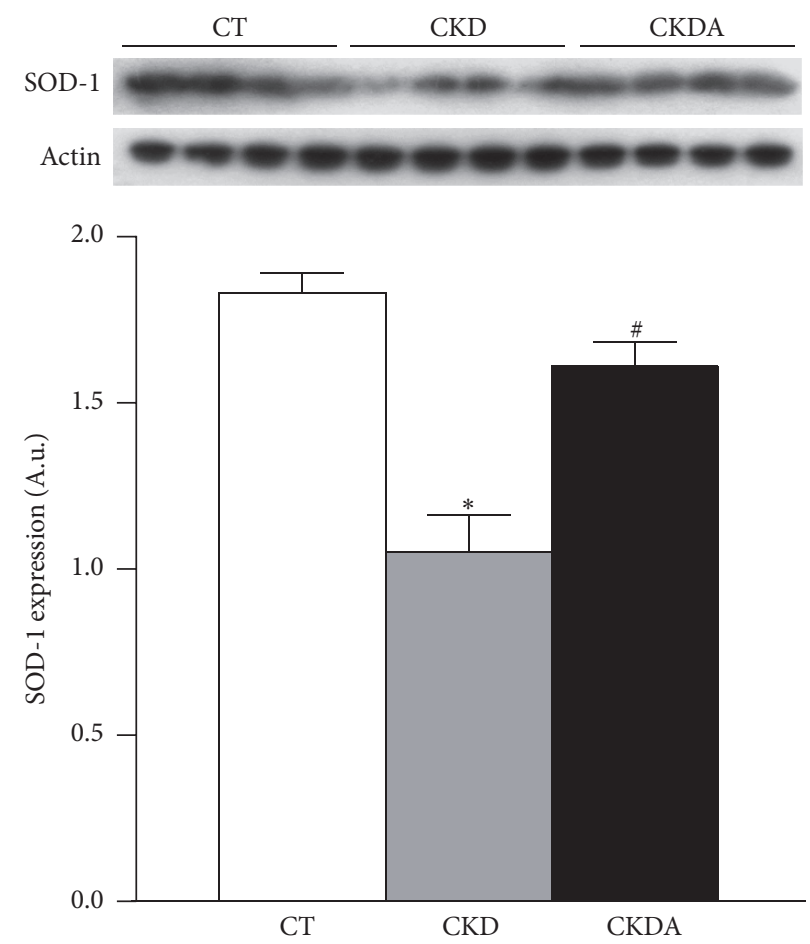

(c)

FIGURE 7: Evaluation of antioxidant enzymes Nrf2-regulated in heart. (a) Catalase (CAT), (b) glutathione peroxidase (GPx), and (c) superoxide dismutase (SOD). CT: control; CKD: chronic kidney disease; CKDA: chronic kidney disease treated with allicin. Values are presented as mean \pm SD of at least 5 animals from each experimental group. ${ }^{*} p<0.05$ versus $\mathrm{CT}$ and ${ }^{*} p<0.05$ versus CKD. 
contractility $[23,24]$. Other studies reported that allicin protected cardiac function and prevented the development of cardiac hypertrophy through ROS-dependent mechanism involving multiple intracellular signaling (ERK1/2, JNK1/2 and PI3/Akt/GSK3 $\beta$ signaling pathways) [25].

On the other hand, it has been described that allicin has vasodilator activity independent of the synthesis of nitric oxide, ATP-sensitive $\mathrm{K}(+)$ channels, activation of cyclooxygenase enzyme, or changes in bronchomotor tone in the pulmonary vascular bed of the rat; meanwhile, its different metabolites do not possess this effect [26, 27]. There is a possibility that allicin may act through another mechanism, specifically through the inhibition of the renin-angiotensin system which plays a significant role in renovascular hypertension. Garlic lowers blood pressure through the reduction in angiotensin converting enzyme activity (ACE) [28], and the effects of vasoconstrictors simultaneously increase the effects of vasodilators. In the $2 \mathrm{~K}-1 \mathrm{C}$ hypertensive rat model, a significant reduction in SBP was noted in garlic-treated rats. This decrease correlates positively with reduction in ACE activity in the serum, aorta, heart, lung, and kidney [29]. However, the capacity of garlic to downregulate the AT1R expression only has been described in streptozotocininduced diabetic rats [30].

Increased oxidative stress in heart from CKD group was evaluated by measuring lipid and protein oxidation, which was correlated with the lower nuclear translocation and expression of Nrf2 a redox-sensitive transcription factor [31]. The allicin treatment decreased the oxidative stress via an increase in Nrf2 expression and decreasing the expression of its repressor Keap1. Moreover, allicin stimulates Nrf2 nuclear translocation and the expression of antioxidant enzymes CAT, SOD, and GPx.

The exact mechanism through which allicin exerts its antioxidant effects has not yet been fully elucidated. Some researchers have suggested that allicin exerts direct antioxidant effects by preventing the formation of free radicals [3234 , the lipid peroxidation through scavenge $\mathrm{OH}$ molecules, and the chain-carrying peroxyl radicals of the substrates by transferring its allylic hydrogen to the oxidized substrate $[35,36]$. Allicin also acts as an indirect antioxidant by inducing increased levels of intracellular glutathione level via the upregulation of phase II detoxifying enzymes in a Nrf2-dependent pathway (hemeoxygenase-1, superoxide dismutase, glutathione peroxidase, glutathione-S-transferases, $\mathrm{NAD}(\mathrm{P}) \mathrm{H}$-quinine oxidoreductase, and $\gamma$-glutamylcysteine synthetase) $[13,37,38]$.

Our data shows that allicin downregulates AT1 and Keap1 possibly as the main mechanism, cardioprotective mechanism. However, we cannot discard that the beneficial effects of allicin may be mediated by an improved endothelial function, vasodilatory effects, downregulation of AT1 receptor, and hence reduction in AT1 activity and by an antioxidant mechanism by itself, or by indirectly stimulating the degradation of Keapl. Therefore, the inhibition of the interaction between Nrf2 and Keap1 favors nuclear Nrf2 translocation to target gene transactivation [39]. All these effects collectively contributed to the beneficial effect of allicin on the heart in CKD.
At our knowledge, this is the first study showing the effects of allicin on cardiac function, on vascular reactivity to Ang II, and on the expression of AT1R and Keap1 in the heart during the experimental CKD. Our findings highlight the potential of allicin to ameliorate the heavy cardiovascular burden in patients with chronic renal failure (CRF). It is known, for example, that hemodialysis contributes to increasing free radical production and to diminishing antioxidant defenses in CRF patients. In this regard, a recent study demonstrated that oxidative stress was the principal risk factor for cardiovascular mortality in a population of elderly patients undergoing hemodialysis and followed up for 4 years [40]. Furthermore, because heart dysfunction secondary to $\mathrm{CRF}$ is a common event, allicin administration could alleviate cardiac complications in some patients.

This study has some limitations. The main limitation is the short bioavailability of allicin. Allicin has a short half-life and it is disintegrated to other compounds such as diallyl sulfide, disulfides, trisulfides, and ajoene [41]. Allicin cannot be detected in the blood or urine after ingestion of raw garlic or pure allicin [42]. To date, there is no assay to measure plasma levels of allicin; thus the correlation with the effects of allicin cannot be ascertained. Finally, whether low doses of allicin than those used in our study can be effective in reducing the blood pressure using a less aggressive experimental model even more chronic still needs to be investigated. Thus, more clinical and animal studies to validate allicin potential use for hypertension management are required.

In conclusion, allicin showed nephroprotective, antihypertensive, cardioprotective, and antioxidant effects, likely mediated by the downregulation of angiotensin II type 1 receptor and the Nrf2-inhibitor Keap1. Furthermore, our data provide evidence supporting the use of allicin as therapy in pathophysiological conditions in which cardiac and/or renal functions may be involved or associated.

\section{Disclosure}

The authors alone are responsible for the content and writing of the paper.

\section{Competing Interests}

The authors report no competing interests.

\section{Acknowledgments}

This study was supported by the National Council of Science and Technology (CONACyT) Mexico, Research Grants 133232 to Laura G. Sánchez-Lozada, 167949 to Edilia Tapia Rodríguez, and 155604 to Horacio Osorio Alonso and by Fondos del Gasto Directo Autorizado a la Subdirección de Investigación Básica, INC "Ignacio Chávez," Fellowship to Ehécatl Miguel Angel García Trejo, CONACyT no. 356810.

\section{References}

[1] E. Di Angelantonio, R. Chowdhury, N. Sarwar, T. Aspelund, J. Danesh, and V. Gudnason, "Chronic kidney disease and risk 
of major cardiovascular disease and non-vascular mortality: prospective population based cohort study," British Medical Journal, vol. 341, p. c4986, 2010.

[2] D. S. Keith, G. A. Nichols, C. M. Gullion, J. B. Brown, and D. H. Smith, "Longitudinal follow-up and outcomes among a population with chronic kidney disease in a large managed care organization," Archives of Internal Medicine, vol. 164, no. 6, pp. 659-663, 2004.

[3] R. N. Foley, P. S. Parfrey, and M. J. Sarnak, "Clinical epidemiology of cardiovascular disease in chronic renal disease," The American Journal of Kidney Diseases, vol. 32, no. 5, supplement 3, pp. S112-S119, 1998.

[4] D. W. Johnson, A.-M. Craven, and N. M. Isbel, "Modification of cardiovascular risk in hemodialysis patients: an evidence-based review," Hemodialysis International, vol. 11, no. 1, pp. 1-14, 2007.

[5] L. Segall, I. Nistor, and A. Covic, "Heart failure in patients with chronic kidney disease: a systematic integrative review," BioMed Research International, vol. 2014, Article ID 937398, 21 pages, 2014.

[6] M. M. Mitsnefes, "Cardiovascular complications of pediatric chronic kidney disease," Pediatric Nephrology, vol. 23, no. 1, pp. 27-39, 2008.

[7] R. E. C. Wildman, Handbook of Nutraceuticals and Functional Foods, Taylor \& Francis, London, UK, 2nd edition, 2006.

[8] A. Bordia, S. K. Verma, A. K. Vyas et al., "Effect of essential oil of onion and garlic on experimental atherosclerosis in rabbits," Atherosclerosis, vol. 26, no. 3, pp. 379-386, 1977.

[9] A. K. Bordia, H. K. Joshi, Y. K. Sanadhya, and N. Bhu, "Effect of essential oil of garlic on serum fibrinolytic activity in patients with coronary artery disease," Atherosclerosis, vol. 28, no. 2, pp. 155-159, 1978.

[10] S. K. Chutani and A. Bordia, "The effect of fried versus raw garlic on fibrinolytic activity in man," Atherosclerosis, vol. 38, no. 3-4, pp. 417-421, 1981.

[11] K. M. Reinhart, C. I. Coleman, C. Teevan, P. Vachhani, and C. M. White, "Effects of garlic on blood pressure in patients with and without systolic hypertension: a meta-analysis," Annals of Pharmacotherapy, vol. 42, no. 12, pp. 1766-1771, 2008.

[12] A. Elkayam, E. Peleg, E. Grossman, Z. Shabtay, and Y. Sharabi, "Effects of allicin on cardiovascular risk factors in spontaneously hypertensive rats," Israel Medical Association Journal, vol. 15, no. 3, pp. 170-173, 2013.

[13] X. Sun and D. D. Ku, "Allicin in garlic protects against coronary endothelial dysfunction and right heart hypertrophy in pulmonary hypertensive rats," American Journal of PhysiologyHeart and Circulatory Physiology, vol. 291, no. 5, pp. H2431H2438, 2006.

[14] R. Argüello-García, O. N. Medina-Campos, N. Pérez-Hernández, J. Pedraza-Chaverrí, and G. Ortega-Pierres, "Hypochlorous acid scavenging activities of thioallyl compounds from garlic," Journal of Agricultural and Food Chemistry, vol. 58, no. 21, pp. 11226-11233, 2010.

[15] E. Tapia, V. Soto, K. M. Ortiz-Vega et al., "Curcumin induces Nrf2 nuclear translocation and prevents glomerular hypertension, hyperfiltration, oxidant stress, and the decrease in antioxidant enzymes in 5/6 nephrectomized rats," Oxidative Medicine and Cellular Longevity, vol. 2012, Article ID 269039, 14 pages, 2012.

[16] A. De Angelis, E. Piegari, D. Cappetta et al., "Anthracycline cardiomyopathy is mediated by depletion of the cardiac stem cell pool and is rescued by restoration of progenitor cell function," Circulation, vol. 121, no. 2, pp. 276-292, 2010.
[17] A. C. Razo-Rodríguez, Y. I. Chirino, D. J. Sánchez-González, C. M. Martínez-Martínez, C. Cruz, and J. Pedraza-Chaverri, "Garlic powder ameliorates cisplatin-induced nephrotoxicity and oxidative stress," Journal of Medicinal Food, vol. 11, no. 3, pp. 582-586, 2008.

[18] A. Y. Nasr and H. A. M. Saleh, "Aged garlic extract protects against oxidative stress and renal changes in cisplatin-treated adult male rats," Cancer Cell International, vol. 14, no. 1, article 92, 2014.

[19] I. Seckiner, O. Bayrak, M. Can, A. G. Mungan, and N. A. Mungan, "Garlic supplemented diet attenuates gentamicin nephrotoxicity in rats," International Brazilian Journal Of Urology, vol. 40, no. 4, pp. 562-567, 2014.

[20] M. Ali, K. K. Al-Qattan, F. Al-Enezi, R. M. A. Khanafer, and T. Mustafa, "Effect of allicin from garlic powder on serum lipids and blood pressure in rats fed with a high cholesterol diet," Prostaglandins Leukotrienes and Essential Fatty Acids, vol. 62, no. 4, pp. 253-259, 2000.

[21] A. Elkayam, D. Mirelman, E. Peleg et al., "The effects of allicin and enalapril in fructose-induced hyperinsulinemic hyperlipidemic hypertensive rats," American Journal of Hypertension, vol. 14, no. 4, pp. 377-381, 2001.

[22] J. Suzuki, H. Matsubara, M. Urakami, and M. Inada, "Rat angiotensin II (type $1 \mathrm{~A}$ ) receptor mRNA regulation and subtype expression in myocardial growth and hypertrophy," Circulation Research, vol. 73, no. 3, pp. 439-447, 1993.

[23] S.-H. Chang, C.-J. Liu, C.-H. Kuo et al., "Garlic oil alleviates MAPKs- and IL-6-mediated diabetes-related cardiac hypertrophy in STZ-induced DM rats," Evidence-Based Complementary and Alternative Medicine, vol. 2011, Article ID 950150, 11 pages, 2011.

[24] L. Supakul, H. Pintana, N. Apaijai, S. Chattipakorn, K. Shinlapawittayatorn, and N. Chattipakorn, "Protective effects of garlic extract on cardiac function, heart rate variability, and cardiac mitochondria in obese insulin-resistant rats," European Journal of Nutrition, vol. 53, no. 3, pp. 919-928, 2014.

[25] C. Liu, F. Cao, Q.-Z. Tang et al., "Allicin protects against cardiac hypertrophy and fibrosis via attenuating reactive oxygen species-dependent signaling pathways," Journal of Nutritional Biochemistry, vol. 21, no. 12, pp. 1238-1250, 2010.

[26] A. D. Kaye, B. J. De Witt, M. Anwar et al., "Analysis of responses of garlic derivatives in the pulmonary vascular bed of the rat," Journal of Applied Physiology, vol. 89, no. 1, pp. 353-358, 2000.

[27] A. D. Kaye, B. D. Nossaman, I. N. Ibrahim et al., "Analysis of responses of allicin, a compound from garlic, in the pulmonary vascular bed of the cat and in the rat," European Journal of Pharmacology, vol. 276, no. 1-2, pp. 21-26, 1995.

[28] M. Hosseini, S. M. Shafiee, and T. Baluchnejadmojarad, "Garlic extract reduces serum angiotensin converting enzyme (ACE) activity in nondiabetic and streptozotocin-diabetic rats," Pathophysiology, vol. 14, no. 2, pp. 109-112, 2007.

[29] A. M. Sharifi, R. Darabi, and N. Akbarloo, "Investigation of antihypertensive mechanism of garlic in $2 \mathrm{~K} 1 \mathrm{C}$ hypertensive rat," Journal of Ethnopharmacology, vol. 86, no. 2-3, pp. 219-224, 2003.

[30] M. H. Mansour, K. Al-Qattan, M. Thomson, and M. Ali, "Garlic (Allium sativum) down-regulates the expression of angiotensin II $\mathrm{AT}_{1}$ receptor in adrenal and renal tissues of streptozotocininduced diabetic rats," Inflammopharmacology, vol. 21, no. 2, pp. 147-159, 2013.

[31] Q. Ma, L. Battelli, and A. F. Hubbs, "Multiorgan autoimmune inflammation, enhanced lymphoproliferation, and impaired 
homeostasis of reactive oxygen species in mice lacking the antioxidant-activated transcription factor Nrf2," American Journal of Pathology, vol. 168, no. 6, pp. 1960-1974, 2006.

[32] T. Miron, M. Wilchek, A. Sharp et al., "Allicin inhibits cell growth and induces apoptosis through the mitochondrial pathway in HL60 and U937 cells," Journal of Nutritional Biochemistry, vol. 19, no. 8, pp. 524-535, 2008.

[33] A. Rabinkov, T. Miron, D. Mirelman et al., "S-Allylmercaptoglutathione: the reaction product of allicin with glutathione possesses SH-modifying and antioxidant properties," Biochimica et Biophysica Acta-Molecular Cell Research, vol. 1499, no. 1-2, pp. 144-153, 2000.

[34] Y. Okada, K. Tanaka, E. Sato, and H. Okajima, "Kinetic and mechanistic studies of allicin as an antioxidant," Organic and Biomolecular Chemistry, vol. 4, no. 22, pp. 4113-4117, 2006.

[35] A. Rabinkov, T. Miron, L. Konstantinovski, M. Wilchek, D. Mirelman, and L. Weiner, "The mode of action of allicin: trapping of radicals and interaction with thiol containing proteins," Biochimica et Biophysica Acta-General Subjects, vol. 1379, no. 2, pp. 233-244, 1998.

[36] K. Prasad, V. A. Laxdal, M. Yu, and B. L. Raney, "Antioxidant activity of allicin, an active principle in garlic," Molecular and Cellular Biochemistry, vol. 148, no. 2, pp. 183-189, 1995.

[37] L. Horev-Azaria, S. Eliav, N. Izigov et al., "Allicin up-regulates cellular glutathione level in vascular endothelial cells," European Journal of Nutrition, vol. 48, no. 2, pp. 67-74, 2009.

[38] X.-H. Li, C.-Y. Li, Z.-G. Xiang et al., "Allicin ameliorates cardiac hypertrophy and fibrosis through enhancing of nrf2 antioxidant signaling pathways," Cardiovascular Drugs and Therapy, vol. 26, no. 6, pp. 457-465, 2012.

[39] H. R. Moinova and R. T. Mulcahy, "Up-regulation of the human $\gamma$-glutamylcysteine synthetase regulatory subunit gene involves binding of Nrf-2 to an electrophile responsive element," Biochemical and Biophysical Research Communications, vol. 261, no. 3, pp. 661-668, 1999.

[40] B. Bayés, M. C. Pastor, J. Bonal, A. Foraster, and R. Romero, "Oxidative stress, inflammation and cardiovascular mortality in haemodialysis - role of seniority and intravenous ferrotherapy: analysis at 4 years of follow-up," Nephrology Dialysis Transplantation, vol. 21, no. 4, pp. 984-990, 2006.

[41] E. Block, "The chemistry of garlic and onions," Scientific American, vol. 252, no. 3, pp. 114-119, 1985.

[42] L. D. Lawson, D. K. Ransom, and B. G. Hughes, "Inhibition of whole blood platelet-aggregation by compounds in garlic clove extracts and commercial garlic products," Thrombosis Research, vol. 65 , no. 2 , pp. 141-156, 1992. 


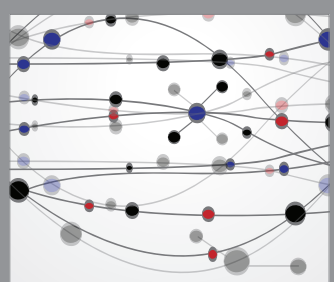

The Scientific World Journal
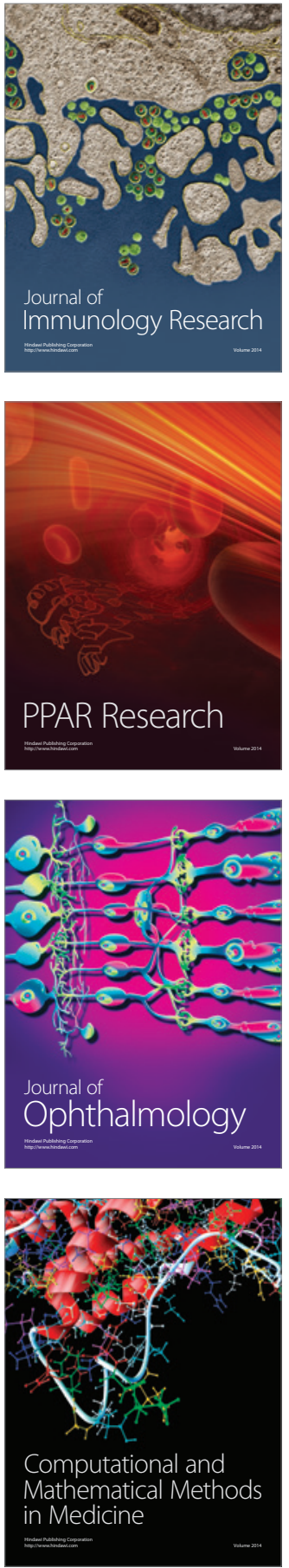

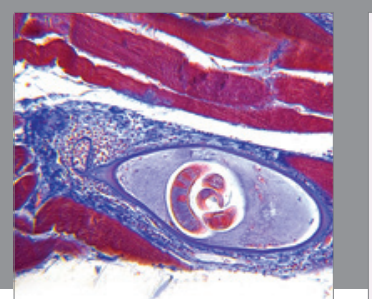

Gastroenterology Research and Practice

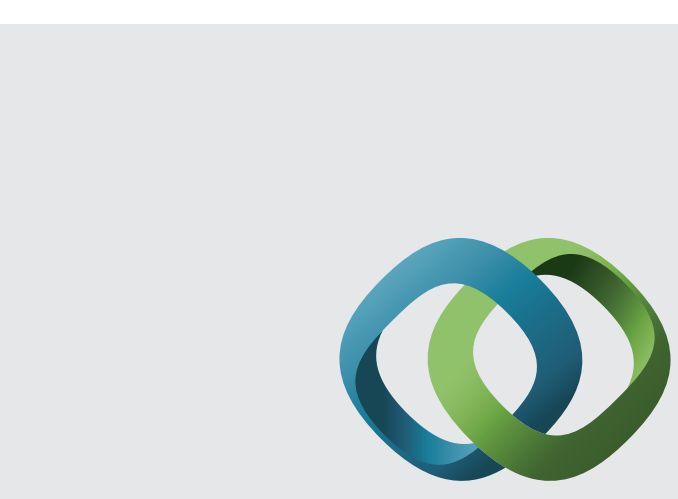

\section{Hindawi}

Submit your manuscripts at

http://www.hindawi.com
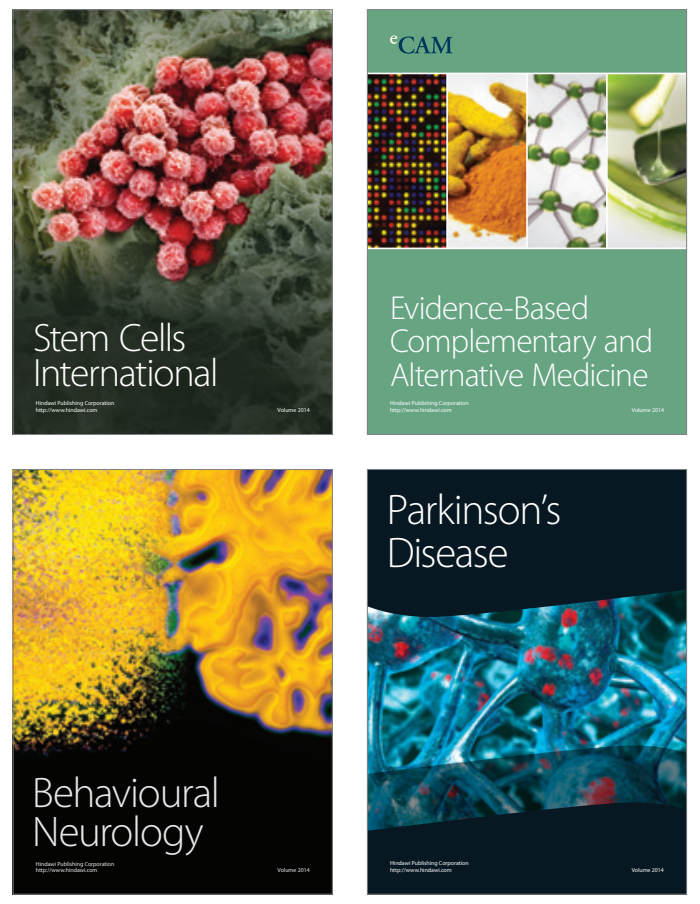
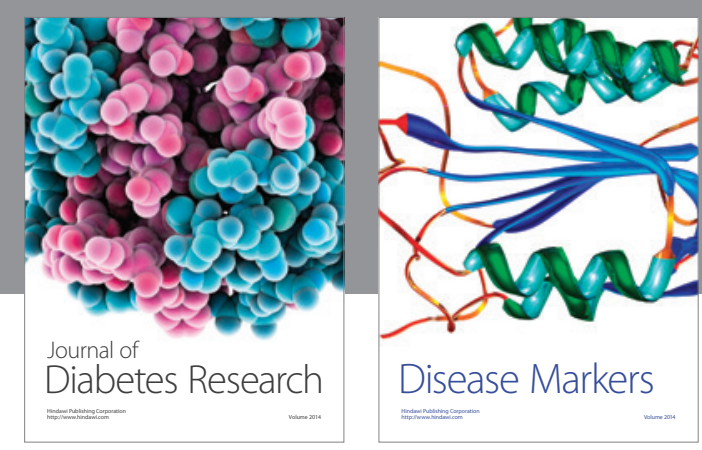

Disease Markers
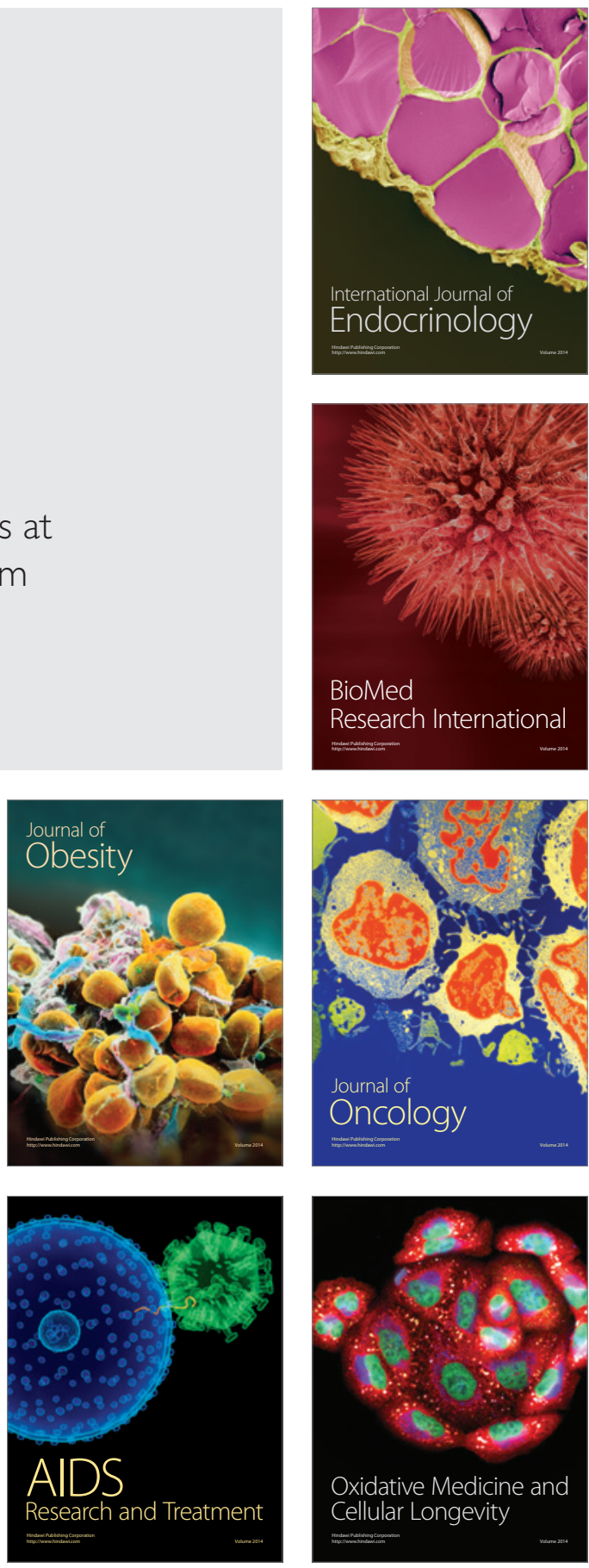